\title{
Crystallization Kinetics of Melt-Blended Low-Density Phthalic Anhydride with a Low-Tg Tin-Phosphate
}

\author{
Laila M. Al-Harbi \\ Chemistry Department, Faculty of Science, King Abdulaziz University, Jeddah, Saudi Arabia \\ Email: Imajeed2002@yahoo.com
}

Received 29 May 2014; revised 29 June 2014; accepted 9 July 2014

Copyright (C 2014 by author and Scientific Research Publishing Inc.

This work is licensed under the Creative Commons Attribution International License (CC BY). http://creativecommons.org/licenses/by/4.0/

(c) (i) Open Access

\begin{abstract}
Polyamide prepared by the reaction of ethylene diamine with different ratios between 1,6-glyconic acid and phthalic anhydride. The differential scanning calorimetry (DSC) is used to study the nonisothermal and isothermal crystallization of low density polyamides in phosphate glass (Pglass)-polymer hybrid blends. The \% crystallinity decreased as the Pglass volume increased. The half-life $\left(t_{1 / 2}\right)$ for crystallization decreased as the propagation rate constant rose for both the polymer matrices with increasing Pglass concentrations. The results show that the Pglass is improved nucleating agent for formation of the Pglass-polymer hybrids up to $35 \%$ Pglass and the energy necessary to break decreased. The stability of the reaction of ethylene diamine with phthalic anhydride and glyconic acid was qualitatively investigated using molecular orbital calculations.
\end{abstract}

\section{Keywords}

Polyamides Crystallinity, Phosphate Glass-Polymer Hybrids, DSC and Kinetics

\section{Introduction}

Polyamides form a class of industrially useful materials because of their excellent properties [1]. Glass is a popular fiber that is blended with commercial thermoplastic such as polyethylene and poly propylene [2]-[4]. Addition of fiber to polymers increases their properties such as increase their temperature resistance, and crystallinity [5].

Recently, the scientists studied the different theoretical variables that have effect on the structure of the polycondenseation polymer, and they concluded that a difference in the reactivity of two functional groups of non- 
symmetrical monomer is necessary to produce condensation polymer with an ordered structure [6], and feedspeed of asymmetric monomer to nonsymmetrical monomer in polymerization is important factor that should be considered [7]. In this work, some polyamides were synthesised by the reaction of different ratios of ethylene diamine with 1,6-glyconic acid and phthalic anhydride. The crystallization behaviour of the material depends on kinetic and properties of hybrids.

\section{Experimental}

\subsection{Materials and Instruments}

Phthalic anhydride, 1,6-gliconic acid and ethylene diamine, all chemical used in this study are of BDH quality. Differential thermal analysis (DTA) of the samples was carried out at heating rate of $10^{\circ} \mathrm{C} / \mathrm{min}$ in nitrogen as an atmosphere using a Shimadzu XD-30 Thermal Analyzer, within the temperature range $25^{\circ} \mathrm{C}-800^{\circ} \mathrm{C}$. Scanning electron micrographs (SEM) of the samples were obtained using a Hitachi S-2460N VP-SEM (Hitachi, Ibaraki, Japan).

\subsection{Preparation of Polyamide}

The polyamide was prepared by the melt condensation of ethylene diamine and phthalic acid with bis 1,6-glyconic acid as recommended [8]. The reaction was conducted in a slow stream of dry deoxygenated nitrogen gas to facilitate the removal of the water produced. When the reaction was completed, the polyamide was dissolved in DMF and then precipitated by adding a large amount of distilled water and stirring. The precipitate was then collected by filtration and dried in a vacuum oven at $40^{\circ} \mathrm{C}$ according to [9].

Densities were measured by means of a pycnometer using hexane at $30^{\circ} \mathrm{C}$. Viscosity measurements were performed with an Ostwald viscometer using a 1\% solution in dioxane and DMF for polyamide resins and polyamide complexes, respectively.

The low-Tg tin-phosphate glass (Pglass), with a molar composition of $0.45 \mathrm{SnF}_{2}+0.25 \mathrm{SnO}+0.30 \mathrm{P}_{2} \mathrm{O}_{5}$, an average density of $3.65 \mathrm{~g} \cdot \mathrm{cm}^{-3}$ and a $\mathrm{Tg}$ of $132.4^{\circ} \mathrm{C}$ (determined using DSC), the polyamide was synthesized with the procedures reported in references [10] [11].

\section{Results and Discussion}

A differential scanning calorimeter was used to determine the crystallization behaviour of the samples. For nonisothermal tests, $10 \mathrm{mg}$ of sample is heated at $50^{\circ} \mathrm{C}$ to 5 minute to eliminate any pre-existing crystals. While for isothermal crystallisation analyses, the samples were quenched to a particular crystallisation temperature (Tc) and held for an amount of time $\left(\mathrm{t}_{\mathrm{c}}\right)$ that depended on the temperature. The information on the crystallisation kinetics was extracted from the raw experimental data. Finally, the samples were reheated above the polymer melting temperature to obtain the data to calculate the equilibrium melting temperature (Tom) as described in [12] Table 1 summarises the thermal history described above for Pglass-glyconic amide (Pglass-GA) 0.5, Pglass-GA 0.7 and Pglass-GA 1.0 hybrids (Pglass-GH). A scan of an indium metal standard at $10^{\circ} \mathrm{C} \cdot \mathrm{min}^{-1}$ was used to check the accuracy of the experiments.

Crystallization exothermic analysis for isothermal crystallization experiments cannot be performed because the matrices of the hybrids of 40\% Pglass in Pglass-glyconic amide 0.5, Pglass-GA 0.7 and Pglass-GA 1.0 these values could not be discernible in crystallizationexotherms. In the nonisothermal experiment the enthalpy of fusion $\Delta$ Hfo was determined by "pyris software"

$$
\% \text { Crystallinity }=\left(\Delta H_{f} / Q_{\text {polymer }} \Delta H_{f}^{\circ}\right) \times 100
$$

where $\Delta H_{f}$ is the enthalpy of polymerization and $Q_{\text {polymer }}$ is the volume fraction of the polymer (Table 1 ).

\subsection{Non Isothermal Crystallization Behavior}

The Pglass-polymer hybrids were concentrated with 0.1, 10, 20 and 40\% of Pglass-polymer. It is clear from Figure 1 that the Pglass-polymer effect the crystallization of polymer GAL and it is slightly higher than that of pure polymer for $Q_{\text {polymer }} 25 \%$ Pglass-polymer, which is due to the small degree of interaction between the 
Table 1. Non-isothermal crystallization from DSC measurements on Pglass-GAL hybrids.

\begin{tabular}{|c|c|c|c|c|c|}
\hline (\%) Pglass Width & $T_{m}\left({ }^{\circ} \mathrm{C}\right)$ & $\Delta H_{f}(\mathrm{~J} / \mathrm{g})$ & (\%) Crystallinity & Onset $\left({ }^{\circ} \mathrm{C}\right)$ & $\left({ }^{\circ} \mathrm{C}\right)$ \\
\hline \multicolumn{6}{|c|}{ Pglass-GAL } \\
\hline 0 & 106.60 & 97.13 & 34.44 & 53.15 & 67.21 \\
\hline 1 & 108.10 & 93.43 & 33.47 & 53.48 & 68.32 \\
\hline 10 & 106.64 & 42.02 & 25.01 & 55.85 & 64.24 \\
\hline 20 & 107.62 & 36.65 & 22.32 & 58.56 & 63.23 \\
\hline 25 & 107.54 & 32.05 & 20.51 & 61.75 & 58.62 \\
\hline 40 & 106.08 & 22.68 & 16.87 & 67.54 & 46.24 \\
\hline \multicolumn{6}{|c|}{ Pglass-GAH } \\
\hline 0 & 166.67 & 87.74 & 44.65 & 105.97 & 88.87 \\
\hline 1 & 167.84 & 89.52 & 46.32 & 95.42 & 83.23 \\
\hline 10 & 166.54 & 75.64 & 41.22 & 91.35 & 76.43 \\
\hline 20 & 165.62 & 66.76 & 38.53 & 88.54 & 70.52 \\
\hline 30 & 162.58 & 48.72 & 28.43 & 90.54 & 57.95 \\
\hline
\end{tabular}

(a)

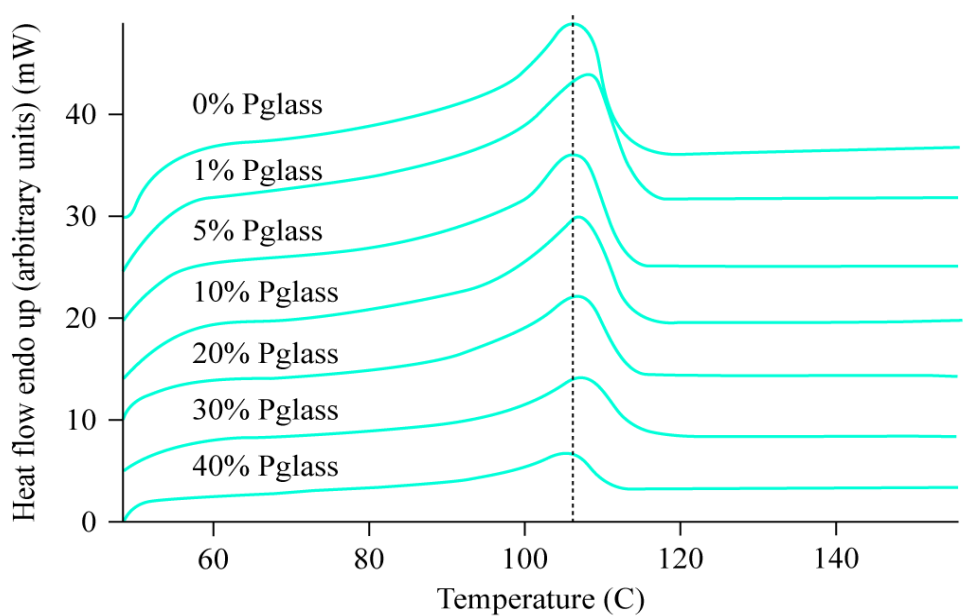

(b)

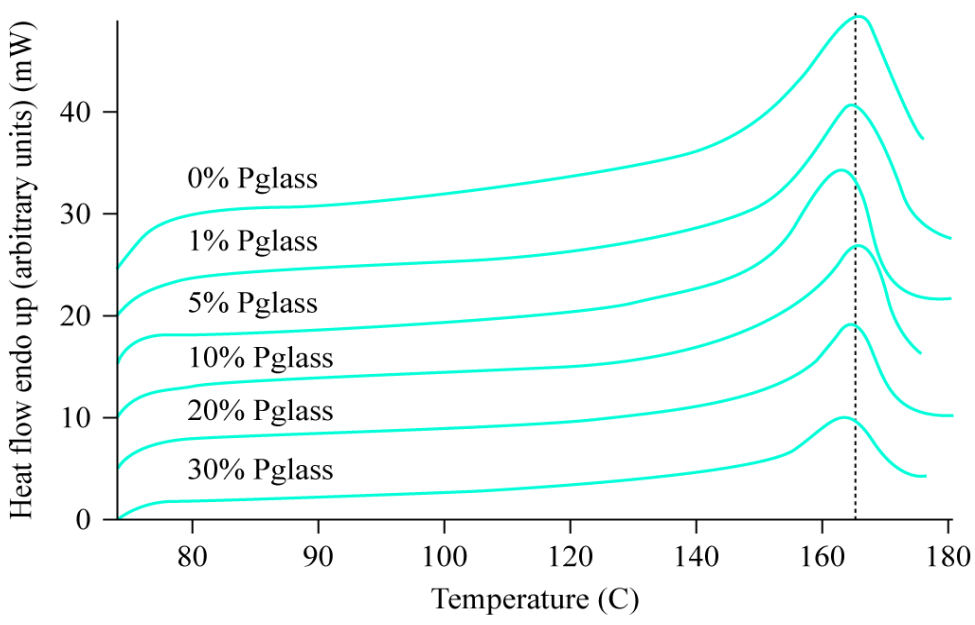

Figure 1. DSC non-isothermal thermograms of (a) Pglass-GAL and (b) PglassGAH hybrids. 


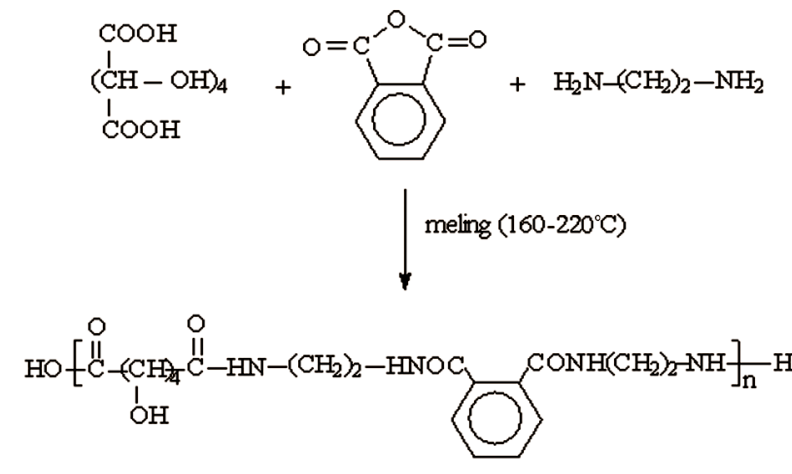

Scheme 1. The reaction mechanism of molten technique.

components as well as that Pglass-polymer droplets may by inducing the formation of larger polymer crystal matric. The addition of Pglass to matrix decrease both the heat of fusion and \% crystallization because it inhibits crystallite formation beyond a particular concentration. Other authors have observed that glass fibres actually increase the crystallinity of some polymer matrices. They attributed this increase in the crystallinity to the formation of some polymer crystallites along the surface of the fiber [2] [3]. The slight increase of the melting temperature due to the presence of a large crystal results in a higher temperature necessary to melt the crystal. The width of the melt endotherm decreases by addition of Pglass which is explained as narrowing of the crystallite size distribution [13]. Comparing the thermal behavior of pure GAH and Pglass hybrid (Figure 1), there is slight decrease in melting temperature as more Pglass which is not significant (no more than 2.6) attributed to the molten Pglass promotes the growth of slightly smaller crystallites in the hybrids compared with GAH.

Figure 1 show melting point at $150^{\circ} \mathrm{C}$ due to the presence of $\beta$-spherulite which disappears after addition of Pglass, followed by main melting pointed at $167^{\circ} \mathrm{C}$ crystallinity ( $\alpha$ and $\beta$ spherulite) decrease (50\% for Pglass-GAL when Q Pglass $=21 \%$, Q Pglass $=25 \%$ Pglass-GAH) when Pglass content increased which may imply that liquid Pglass is less of a hindrance to GAH chain mobility than the solid Pglass phase is to GAL.

The glass-transition temperature of Pglass is higher than the melting temperature of the GAL and lower than that of the GAH. Hence, the GAL crystallites are produced in the presence of a solid Pglass phase, and the GAH crystallites are generated while the Pglass is in the molten state (Scheme 1).

\subsection{Isothermal Crystallisation Behaviour}

To describe the kinetics of the crystallization behaviour, Avrami's equation was employed to show the correct relationship between the degree of crystallisation $X$ and $t$ [14].

$$
X_{c}(t, T)=1-\exp [-(k t) n]
$$

where the $k$ and $n$ parameters are constants: $k$ (units of $\mathrm{s}^{-1}$ ) is defined as the propagation rate constant of the crystal, and $n$ (dimensionless) is a number that depends on the nucleation, geometry and control of the growth process.

$X$ is defined as the time- and temperature-dependent ratio of the crystallized mass to the original amorphous polymer mass. Avrami treated intermediate heterogeneous nucleation cases in which the rate of nucleation decreases exponentially with time [14]. An analysis of the relative crystallinity at each temperature was performed through the division of the area of the crystallization peak (at various times) by the value of the theoretical heat of melting over the entire thermogram area, represented by the following equation:

$$
X_{C}=\frac{\int_{0}^{1}\left(\frac{\mathrm{d} H}{\mathrm{~d} t}\right) \mathrm{d} t}{\int_{0}^{m}\left(\frac{\mathrm{d} H}{\mathrm{~d} t}\right) \mathrm{d} t}
$$

Because this equation yields a mass fraction of crystallinity, one must convert it to a volume fraction for consistency in the use of Equation (2): 


$$
X v_{c}=X m_{c} P_{a} / P_{c}-X m_{c}\left(P_{c}-P_{a}\right)
$$

where $P_{a}$ and $P_{c}$ represent the amorphous and crystalline densities, respectively, and the subscripts $v_{c}$ and $m_{c}$ are the volume and mass fractions of crystallinity, respectively. Through application of the Avrami equation to the partially integrated heat flow changes during isothermal crystallization, the parameters $k$ and $n$ could be determined. The rearrangement of Equation (2) by applying a double logarithm to both sides of the equation yields a linear form with variables $\operatorname{Ln}[-\ln (1-X)]$ and $\operatorname{Lnt}$, slope $\mathrm{n}$ and intercept $n \operatorname{Ln} k$. Once the $k$ and $n$ parameters are known, the half-time $\left(t_{1 / 2}\right)$, which is the time required to obtain a relative crystallinity of $50 \%(X=0.5)$, can be found. Applying this value to Equation (2) gives the following equation:

$$
t_{1 / 2}=(\ln 2) 1 / n / k
$$

For the isothermal kinetics studies, hybrids with Pglass concentrations of 0, 1, 10, 25 and 40 vol\% were tested in the temperature range of $85^{\circ} \mathrm{C}$ to $105^{\circ} \mathrm{C}$ (Pglass-GAL hybrids). In experiments performed at temperatures below $85^{\circ} \mathrm{C}$, the crystallization occurred too quickly to measure it accurately, and above $100^{\circ} \mathrm{C}$, the crystallisation was too slow. However, stable thermograms were obtained for the following temperatures: $92^{\circ} \mathrm{C}, 98^{\circ} \mathrm{C}$ and $105^{\circ} \mathrm{C}$. Figure 2(a) shows the Pglass-GAL thermograms at $92^{\circ} \mathrm{C}$.

The Pglass affects the crystallization kinetics of GAL crystals; the minimum position of the heat flow of the thermograms is observed to shift to the left as more Pglass is added. The time needed for the crystallization peak to develop is a strong function of temperature such that at higher temperatures, more crystallization time is required. The higher degree of thermal energy that the material possesses at higher melt crystallization temperatures inhibits the crystal growth. Once sufficient energy has dissipated during the quenching and subsequent cooling, the crystal growth increases. Table 2 shows the results of the isothermal crystallization analysis of the Pglass-GAL hybrids and lists the Avrami parameters and their dependence on the Pglass content. The Avrami exponent $n$ of the pure GAL remained within the range of 1.64 and 2.38 for all crystallization and Pglass concentrations, suggesting instantaneous, heterogeneous, two-directional, and diffusion-controlled crystallite growth in a disc-like growth geometry. The addition of Pglass appears to reduce the value of the exponent slightly at crystallization temperatures of $92^{\circ} \mathrm{C}$ and $98^{\circ} \mathrm{C}$ and to increase it at $\mathrm{T}_{\mathrm{C}}=102^{\circ} \mathrm{C}$, but overall, the exponent does not appear to change very much with Pglass concentration.

The crystallization rate constant $k$ shows an increase in value with Pglass concentration, with more pronounced trends at higher crystallization temperatures.

Further evidence of a hastened crystallization of the GAL phase is found in the $t_{1 / 2}$ data [Table 2]. The halftime behaves inversely to the rate constant in that it decreases with Pglass content in a more pronounced manner at higher crystallization temperatures. Ultimately, the Pglass causes faster crystal growth as more is added to the matrix, but it does not permit the formation of new GAL crystals.

Figures 3(a) and Figures 3(b) show optical micrographs of the morphology of pure GAL and a 1\% PglassGAL hybrid, respectively. There is a profound decrease in the spherulitic structure of the Pglass-GAL hybrid, which is attributed to the addition of only 1\% Pglass to the GAL matrix in Figure 3(b).

The Pglass-GAH hybrids with Pglass concentrations of 0, 1, 10, 25 and 40 vol\% were tested in the temperature range of $125^{\circ} \mathrm{C}$ to $140^{\circ} \mathrm{C}$. Figure 2(b) shows an example of the Pglass-GAH thermograms at $135^{\circ} \mathrm{C}$. This graph alone clearly shows that Pglass has a more profound effect on the crystallization kinetics of GAH than GAL. According to the calculated Avrami parameters in Table 2, the rate constant $k$ and half-time of crystallization $t_{1 / 2}$ change with Pglass content, as was observed with the Pglass-GAL hybrids.

The key difference between the two hybrid systems studied is that this effect is suppressed as the crystallization temperature is increased for the Pglass-GAH hybrid. The main observation of the data presented above is the significant decrease in the half-time of crystallization with Pglass concentration, as noted by the shift in the minimum position of the isothermal exotherms. The marked difference in crystal growth rate between the Pglass-polymer hybrids may be attributed to the phase of the Pglass. This very large interface can be expected to provide sites for numerous covalent bonds or other compatibilisation between phases. The exponent appears to fall within the range of 3.0 - 4.0 at all three temperatures and Pglass compositions according to Table 2, signifying homogenous, three-dimensional, interface-controlled growth. Figure 4(a) and Figure 4(b) show the spherulite growth for pure GAH and for the 1\% Pglass-GAH hybrid, respectively. Figure 4(b) reveals that the crystals grow at and around the Pglass interface. An enlargement of one of the Pglass droplets with GAH crystals at the interface is shown in Figure 4(c), confirming the presence of spherical crystallites. 

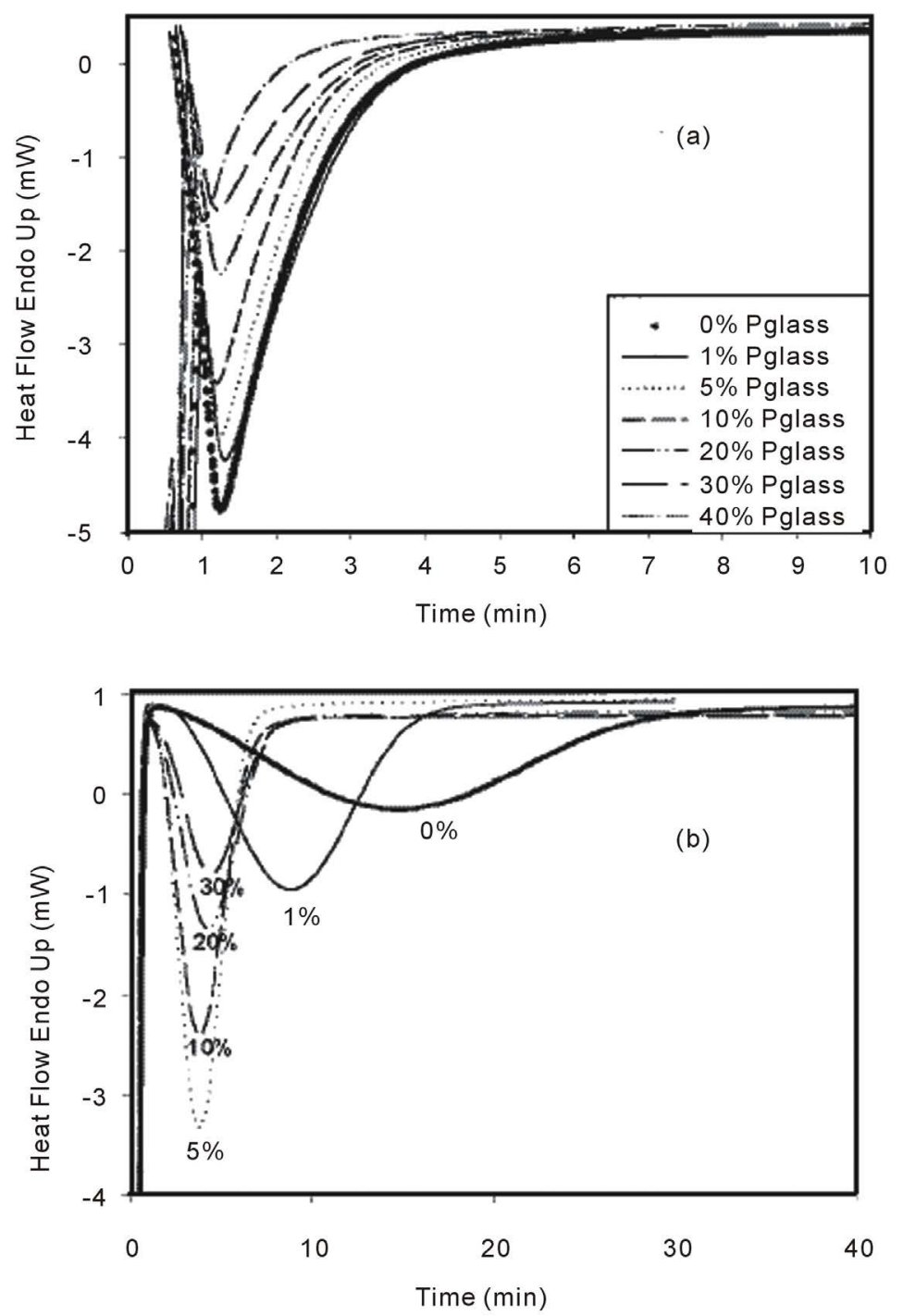

Figure 2. DSC isothermal thermograms of (a) Pglass-GAL hybrids at $T_{c}$.

Table 2. Isothermal crystallization kinetic parameters from DSC measurements on Pglass-GAL and Pglass-GAH hybrids.

\begin{tabular}{|c|c|c|c|c|c|c|c|c|c|}
\hline \multirow{2}{*}{ Pglass (\%) } & \multicolumn{3}{|c|}{$\mathrm{T}_{\mathrm{c}}=92^{\circ} \mathrm{C}$} & \multicolumn{3}{|c|}{$\mathrm{T}_{\mathrm{c}}=98^{\circ} \mathrm{C}$} & \multicolumn{3}{|c|}{$\mathrm{T}_{\mathrm{C}}=102^{\circ} \mathrm{C}$} \\
\hline & $\mathrm{n}$ & $\mathrm{K}\left(\mathrm{s}^{-1}\right)$ & $\mathrm{t}_{1 / 2}(\mathrm{~min})$ & $\mathrm{n}$ & $\mathrm{K}\left(\mathrm{s}^{-1}\right)$ & $\mathrm{t}_{1 / 2}(\min )$ & $\mathrm{n}$ & $\mathrm{K}\left(\mathrm{s}^{-1}\right)$ & $\mathrm{t}_{1 / 2}$ (min) \\
\hline \multicolumn{10}{|c|}{ Pglass-GAL } \\
\hline 0 & 2.32 & 0.435 & 1.92 & 1.90 & 0.175 & 4.35 & 1.62 & 0.072 & 9.56 \\
\hline 1 & 3.29 & 0.431 & 1.90 & 1.88 & 0.181 & 4.29 & 1.58 & 0.069 & 10.45 \\
\hline 10 & 3.35 & 0.448 & 1.85 & 1.79 & 0.177 & 3.86 & 1.65 & 0.102 & 8.63 \\
\hline 25 & 2.24 & 0.418 & 1.96 & 1.84 & 0.220 & 3.58 & 2.06 & 0.105 & 7.54 \\
\hline 40 & 2.16 & 0.456 & 1.86 & 1.44 & 0.193 & 3.84 & 2.126 & 0.142 & 6.65 \\
\hline \multicolumn{10}{|c|}{ Pglass-GAH } \\
\hline 0 & 2.42 & 0.425 & 1.82 & 1.80 & 0.165 & 4.25 & 1.64 & 0.082 & 9.56 \\
\hline 1 & 2.24 & 0.418 & 1.96 & 1.84 & 0.220 & 3.58 & 2.06 & 0.105 & 7.54 \\
\hline 10 & 2.32 & 0.435 & 1.92 & 1.90 & 0.175 & 4.35 & 1.62 & 0.072 & 10.56 \\
\hline 25 & 3.29 & 0.431 & 1.90 & 1.88 & 0.181 & 4.29 & 1.58 & 0.069 & 10.45 \\
\hline 40 & 3.35 & 0.448 & 1.85 & 1.79 & 0.177 & 3.86 & 1.65 & 0.102 & 8.63 \\
\hline
\end{tabular}



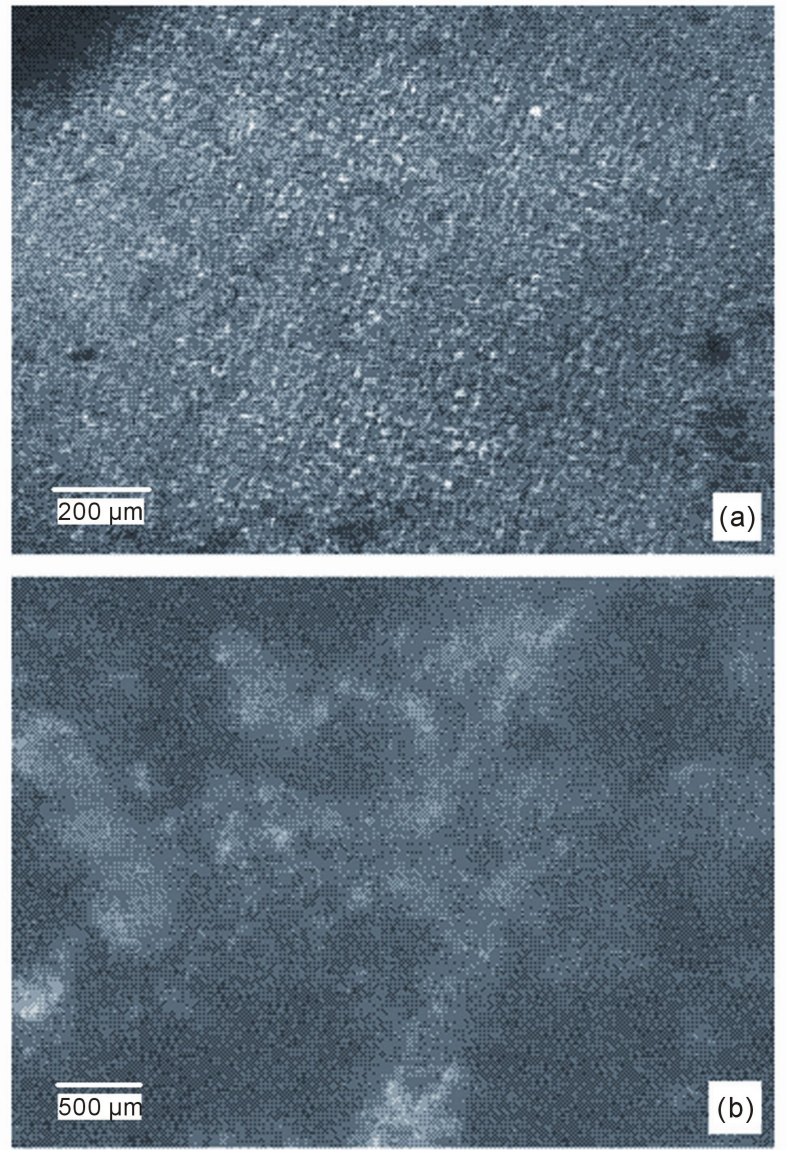

Figure 3. Optical micrographs showing crystallization of (a) pure GAL and (b) $1 \%$ Pglass in $\mathrm{GAL}=92^{\circ} \mathrm{C}$ and Pglass-GAH at $\mathrm{T}_{\mathrm{C}}=102^{\circ} \mathrm{C}$.
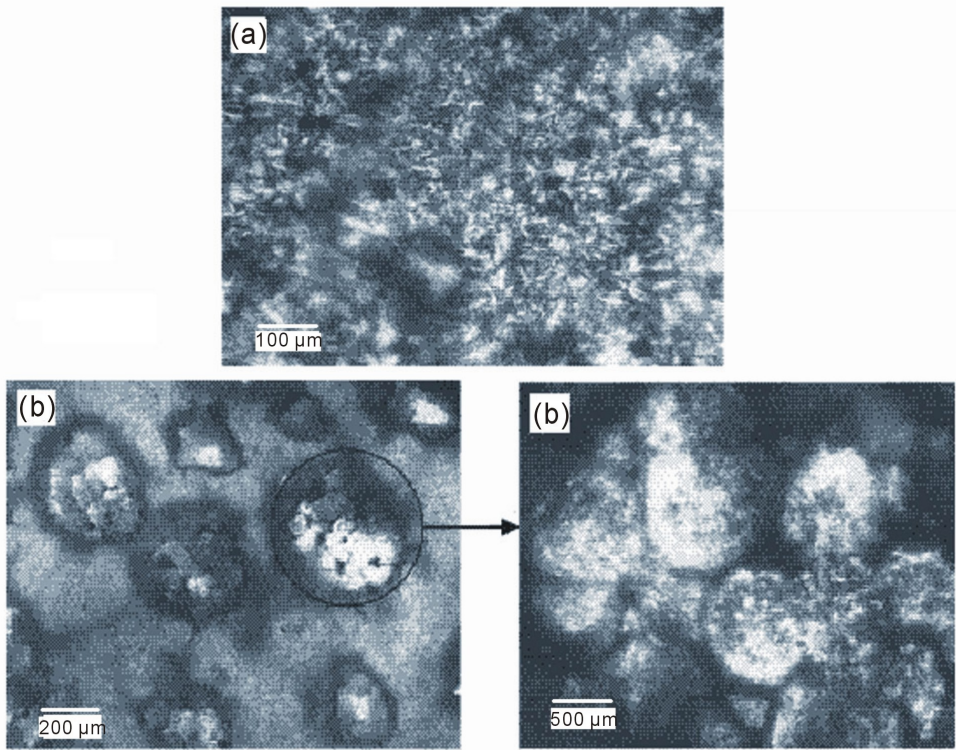

Figure 4. Optical micrographs showing crystallization of (a) pure GAH and (b) $1 \%$ Pglass in GAH. (c) represents an enlargement of a section of (b). 


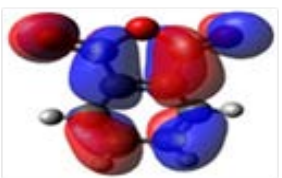

Phthalic anhydride $\left(\right.$ LUMO $\left._{P A}=-2.66 \mathrm{eV}\right)$

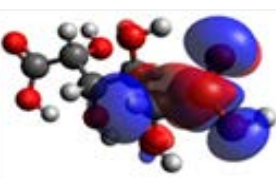

Glyconic acid

(LUMOGA $=-1.017 \mathrm{eV}$ )

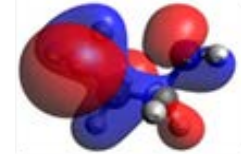

Ethylene diamine

$\left(\mathrm{HOMO}_{\mathrm{EDA}}=-5.90 \mathrm{eV}\right.$

Figure 5. the LUMO and HOMO of phythalicanhydride ,Glyconic acid and Ethylene diamine.

\subsection{Theoretical Calculations}

The stability of the reaction of Ethylene diamine with phthalic anhydride and glyconic acid was qualitatively investigated using molecular orbital calculations. Geometry optimization for ethylene diamine, phthalic anhydride and glyconic acid were carried out using Density Functional Theory with the Backle3LYP hybrid functional, by using a basis set of 6-31G (d) [15]. Geometry optimization was followed by frequency calculations for each structure. The frequency calculations indicated no imaginary frequencies hence emphasizing that the structures are global minimum structures. Computations have been performed using the Gaussian 09 Revision D.01 program package. The optimized geometry of the ethylene diamine along with HOMO and phthalic anhydride and glyconic acid along with LUMO are depicted in the Figure 5. HOMO of ethylene diamine is the electrondonor orbital and is concentrated on the NH2 group. The LUMO of phthalic anhydride reveals electron-acceptor orbital which resides on the carbonyl group and in the case of glyconic acid, the LUMO resides on the carboxylate group. The energies of the frontier orbitals of the donor and the acceptors along with the energy corresponds to the energy gap

$$
\begin{aligned}
& \Delta E\left(\mathrm{HOMO}_{\mathrm{EDA}}-\mathrm{LUMO}_{\mathrm{PA}}\right)=-3.24 \mathrm{eV} \\
& \Delta E\left(\mathrm{HOMO}_{\mathrm{EDA}}-\mathrm{LUMO}_{\mathrm{GA}}\right)=-4.88 \mathrm{eV}
\end{aligned}
$$

The shape of the frontier orbitals shown in the figure and the negative value of the energy gap is indicative of the feasibility of the chemical reaction.

\section{Conclusion}

The crystallization behavior of semi crystalized polymers GAL and GAH changed due to presence of Pglass which acts as nucleation agent. The optical microscopy and differential scanning calorimetry (DSC) conforms the increase of Avrami index due to the change in growth geometry from 2D to 3D spherulites. From nonisothermal crystallization, it was concluded that the solid Pglass phase induced the formation of narrow distribution of large crystal in Pglass-GAL hybrid instead of narrow distribution of small crystallization in Pglass-GAH hybrid.

\section{References}

[1] Allen, G. and Bevinton, J.C. (Eds.) (1989) Comprehensive Polymer Science. Pergamon Press, Oxford, Vol. 5, 97.

[2] Avalos, F., Lopez-Manchado, M.A. and Arroyo, M. (1998) Crystallization Kinetics of Polypropylene III. Ternary Composites Based on Polypropylene/Low Density Polyethylene Blend Matrices and Short Glass Fibres. Polymer, 39, 6173-6178. http://dx.doi.org/10.1016/S0032-3861(98)00098-6

[3] Gupta, A.K., Gupta, V.B., Peters, R.H., Harland, W.G., Berry, J.P. (1982) The Effect of Addition of High-Density Polyethylene on the Crystallization and Mechanical Properties of Polypropylene and Glass-Fiber-Reinforced Polypropylene. Journal of Applied Polymer Science, 27, 4669-4686. http://dx.doi.org/10.1002/app.1982.070271214

[4] Tai, H.-J., Chiu, W.-Y., Chen, L.-W. and Chu, L.-H. (1991) Study on the Crystallization Kinetics of PP/GF Composites. Journal of Applied Polymer Science, 42, 3111-3122. http://dx.doi.org/10.1002/app.1991.070421205

[5] Guschl, P.C. and Otaigbe, J.U. (2002) An Experimental Study of Morphology and Rheology of Ternary PglassPS-LDPE Hybrids. Polymer Engineering \& Science, 43, 1180. http://dx.doi.org/10.1002/pen.10100

[6] Khalil, A.A. (2011) Synthesis, Exchange Reactions, and Biological Activity of Poly(8-Methacryloxyquinoline). Journal of Applied Polymer Science, 121, 1160-1165. http://dx.doi.org/10.1002/app.33624 
[7] Gentle, F.T. and Suter, U.W. (1989) Comprehensive Polymer Science. Pergamon Press, Oxford.

[8] Rothon, R.N. (1995) Particulate-Filled Polymer Composites. Longman, Harlow, UK.

[9] Denault, J. and Vu-Khanh, T. (1992) Crystallization Behavior and Effect of Thermal Treatment on Fracture Performance of Glass Flake Reinforced Polypropylene. Polymer Composites, 13, 372-379. http://dx.doi.org/10.1002/pc.750130506

[10] Frank, J.W. (1965) The Analytical Use of Ethylenediaminetetracetic Acid. Van Nostrand, New York.

[11] Badr, S.K. (2005) Synthesis and Characterization of Polyamide(1,6-Gliconic Acid) with Some Metal Ion Complexes. Oriental Journal of Chemistry, 21, 55-60.

[12] Guschl, P.C. and Otaigbe, J.U. (2003) Crystallization Kinetics of Low-Density Polyethylene and Polypropylene MeltBlended with a Low-Tg Tin-Based Phosphate Glass. Journal of Applied Polymer Science, 90, 3445-3456. http://dx.doi.org/10.1002/app.13084

[13] El-Mossalamy, E.H. and Khalil, A.A. (1996) Synthesis and Investigation of N-Methylacryloyloxytetrabromophthalimide Polymer Complexes with Some Transition Metal Chlorides. European Polymer Journal, 32, 397-400. http://dx.doi.org/10.1016/0014-3057(95)00197-2

[14] Adalja, S.B., Otaigbe, J.U. and Thalacker, J. (2001) Glass-Polymer Melt Hybrids. I: Viscoelastic Properties of Novel Affordable Organic-Inorganic Polymer hybrids. Polymer Engineering \& Science, 41, 1055-1067. http://dx.doi.org/10.1002/pen.10806

[15] Frisch, M.J., Trucks, G.W., Schlegel, H.B., Scuseria, G.E., Robb, M.A., Cheeseman, J.R., et al. (2003) Gaussian 03, Revision B.04. Gaussian, Inc., Pittsburgh. 
Scientific Research Publishing (SCIRP) is one of the largest Open Access journal publishers. It is currently publishing more than 200 open access, online, peer-reviewed journals covering a wide range of academic disciplines. SCIRP serves the worldwide academic communities and contributes to the progress and application of science with its publication.

Other selected journals from SCIRP are listed as below. Submit your manuscript to us via either submit@scirp.org or Online Submission Portal.
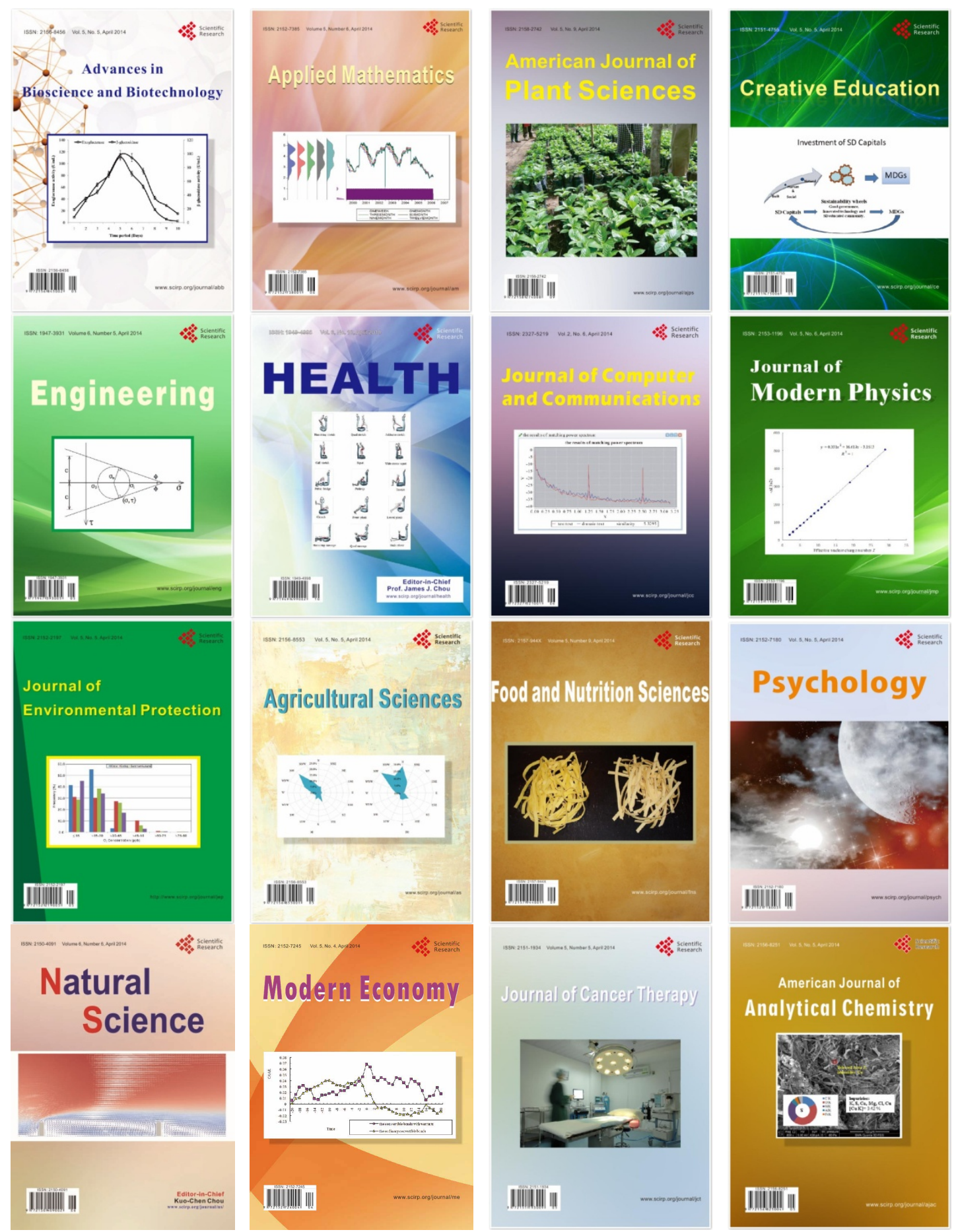